Research Article

\title{
Screening for germline BRCA1, BRCA2, TP53 and CHEK2 mutations in families at-risk for hereditary breast cancer identified in a population-based study from Southern Brazil
}

Edenir Inêz Palmero ${ }^{1,2,3,4,5}$, Bárbara Alemar ${ }^{1,2}$, Lavínia Schüler-Faccini ${ }^{1,6,7}$, Pierre Hainaut ${ }^{3}$, Carlos Alberto Moreira-Filho $^{8-9}$, Ingrid Petroni Ewald ${ }^{2}$, Patricia Koehler dos Santos ${ }^{1,2}$, Patricia Lisbôa Izetti Ribeiro ${ }^{2}$, Cristina Brinkmann de Oliveira Netto ${ }^{6}$, Florence Le Calvez-Kelm ${ }^{3}$, Sean Tavtigian ${ }^{3}$, Silvia Liliana Cossio ${ }^{2,10}$, Roberto Giugliani ${ }^{1,6,7}$, Maira Caleffi ${ }^{11}$, Patricia Ashton-Prolla ${ }^{1,2,6,7}$

${ }^{1}$ Programa de Pós Graduação em Genética e Biologia Molecular, Universidade Federal do Rio Grande do Sul, Porto Alegre, RS, Brazil.

${ }^{2}$ Laboratório de Medicina Genômica, Hospital de Clinicas de Porto Alegre, Porto Alegre, RS, Brazil.

${ }^{3}$ Cluster of Molecular Carcinogenesis, International Agency for Research on Cancer, Lyon, France

${ }^{4}$ Centro de Pesquisa em Oncologia Molecular, Hospital de Câncer de Barretos, Barretos, SP, Brazil

${ }^{5}$ Faculdade de Ciências da Saúde Dr. Paulo Prata, São Paulo, SP, Brazil.

${ }^{6}$ Serviço de Genética Médica, Hospital de Clinicas de Porto Alegre, Porto Alegre, RS, Brazil.

${ }^{7}$ Departmento de Genética, Universidade Federal do Rio Grande do Sul, Porto Alegre, RS, Brazil

${ }^{8}$ Centro de Pesquisa Experimental, Instituto de Educação e Pesquisa Albert Einstein, São Paulo, SP, Brazil.

${ }^{9}$ Departmento de Imunologia, Instituto de Ciências Biomédicas, Universidade de São Paulo,

São Paulo, SP, Brazil.

${ }^{10}$ Programa de Pós Graduação em Gastroenterologia, Universidade Federal do Rio Grande do Sul, Porto Alegre, RS, Brazil.

${ }^{11}$ Nucleo Mama Porto Alegre e Associação Hospitalar Moinhos de Vento, Porto Alegre, RS, Brazil.

\begin{abstract}
In Brazil, breast cancer is a public health care problem due to its high incidence and mortality rates. In this study, we investigated the prevalence of hereditary breast cancer syndromes (HBCS) in a population-based cohort in Brazils southernmost capital, Porto Alegre. All participants answered a questionnaire about family history (FH) of breast, ovarian and colorectal cancer and those with a positive $\mathrm{FH}$ were invited for genetic cancer risk assessment (GCRA). If pedigree analysis was suggestive of HBCS, genetic testing of the BRCA1, BRCA2, TP53, and CHEK2 genes was offered. Of 902 women submitted to GCRA, 214 had pedigrees suggestive of HBCS. Fifty of them underwent genetic testing: 18 and 40 for BRCA1/BRCA2 and TP53 mutation screening, respectively, and 7 for CHEK2 1100delC testing. A deleterious BRCA2 mutation was identified in one of the HBOC probands and the CHEK21100delC mutation occurred in one of the HBCC families. No deleterious germline alterations were identified in BRCA1 or TP53. Although strict inclusion criteria and a comprehensive testing approach were used, the suspected genetic risk in these families remains unexplained. Further studies in a larger cohort are necessary to better understand the genetic component of hereditary breast cancer in Southern Brazil.
\end{abstract}

Keywords: Breast cancer predisposition syndrome, hereditary breast cancer, genetic cancer risk assessment.

Received: December 12, 2014; Accepted: November 24, 2015.

\section{Introduction}

Breast cancer (BC) is a significant health care problem worldwide, and approximately 1.67 million new cases

Send correspondence to Edenir Inêz Palmero. Centro de Pesquisa em Oncologia Molecular, Hospital de Câncer de Barretos, Av Antenor Duarte Vilela, 1331, 14784-400 Barretos, SP, Brazil. E-mail: edenirip@yahoo.com.br were diagnosed in 2012, representing $25 \%$ of all cancers (Globocan). In Latin America, BC is the most prevalent solid tumor diagnosed in women in the majority of countries (Goss et al., 2013). In Brazil, 51,120 new BC diagnoses were estimated for 2014, and the disease is the first cause of death by cancer in women of all ages, especially in young women, under the age of 50 years (DataSUS, 2014; INCa, 2014). The South and Southeast regions of Brazil 
have the highest $\mathrm{BC}$ incidence rates: 70.98 and 71.98 cases in 100,000 women respectively (INCa, 2014). In comparison to national figures, Rio Grande do Sul, the southernmost State, presents high BC incidence $(87.12: 100,000)$ and mortality rates (13.18:100,000), adjusted rates in 2011 (INCa, 2014).

An estimated 5-10\% of all BCs are hereditary, i.e. caused by germline mutations in high-penetrance cancer predisposition genes (King et al., 2003). Of these, the more prevalent mutations are in BRCA1 (OMIM\#113705) and BRCA2 (OMIM\#600185) (Miki et al., 1994; Wooster et al., 1994), tumor suppressor genes which are associated with hereditary breast and ovarian cancer (HBOC) syndrome. Lifetime risks of breast and ovarian cancer are as high as $65-85 \%$ in $B R C A 1$ and $45-85 \%$ in $B R C A 2$ mutation carriers (Antoniou et al., 2006; Cass et al., 2003; Euhus and Robinson, 2013). To date, over 3.000 distinct germline mutations, polymorphisms and sequence variants have been described in BRCA1 and BRCA2, spread throughout both genes (Breast Cancer Information Core, BIC, 2014). Most are point mutations, small insertions or deletions. However, large genomic deletions and duplications involving one or more exons of $B R C A 1$, and less commonly, BRCA2, have been reported (Gutiérrez-Enríquez et al., 2007; PreislerAdams et al., 2006; Thomassen et al., 2006). Most of these mutations are caused by recombination events involving Alu repeats that are particularly numerous in the $B R C A 1$ locus (Payne et al., 2000). The proportion of genomic rearrangements over all BRCA1 gene mutations in HBOC families seems to be population-dependent varying from $2 \%$ in a series of American families (Hendrickson et al., 2005 ) to $36 \%$ in Dutch patients (Petrij-Bosch et al., 1997). In Rio de Janeiro, (Moreira et al., 2012) screened 168 BC affected women for BRCA2 c.156_157insAlu and found 3 unrelated carriers. Other studies have screened cohorts of Brazilian BC patients for specific mutations, or have focused on some subgroups (for example young women) (Carraro et al., 2013; Ewald et al., 2011; Gomes et al., 2007 ) but the exact prevalence of any $B R C A$ mutation remains largely unknown.

Besides $B R C A 1$ and $B R C A 2$, inherited mutations in other tumor suppressor genes also increase the risk for breast cancer and other tumors. Highly penetrant, hereditary breast cancer genes include PTEN (Cowden's syndrome), TP53 (Li-Fraumeni syndrome), STK11 (PeutzJeghers syndrome) and $C D H 1$ (Hereditary diffuse gastric cancer. Germline mutations in $C H E K 2$ gene are associated with a modest increase in the risk of breast (15-25\% lifetime risk) and colorectal cancer in the hereditary breast and colon cancer syndrome (HBCC) (Euhus and Robinson, 2013; Meijers-Heijboer et al., 2003).

In this study, we analyzed a population-based cohort of women recruited from primary health care units in Porto Alegre who were referred to genetic cancer risk assessment (GCRA) whenever they had a positive family history for breast, ovarian and colorectal cancer (Palmero et al., 2009). Those women with pedigrees suggestive of a hereditary breast cancer predisposition syndrome were offered genetic testing for germline mutations in one or more of the main breast cancer predisposition genes (BRCA1, BRCA2, TP53, PTEN and CHEK2). Our aim was to evaluate the prevalence of hereditary breast cancer phenotypes and breast cancer predisposition gene variations among at-risk women recruited from a population-based cohort in a region with high breast cancer incidence.

\section{Subjects and Methods}

\section{Patient Recruitment}

In 2004, a large population-based cohort study (the Núcleo Mama Porto Alegre-NMPOA-Cohort) was started in Porto Alegre, Southern Brazil, through a partnership between government, non-profit community-based organizations, universities and private entities. This prospective cohort intends to collect demographic and epidemiological data of a large sample of women and test a model for community- based breast cancer screening in an underserved population (Caleffi et al., 2010) (Smith et al., 2006) in an attempt to ultimately decrease BC mortality rates in this region. The study recruited women above the age of 15 years who sought health care in 18 primary health care units (PCUs) located in specific city regions within a 24-month period. Family history (FH) of breast, ovarian and colorectal cancer was assessed in women (above age 15 years) seen in 18 primary health care units from the region by a brief questionnaire and is the basis for the study described elsewhere as the Genetic Cancer Risk Assessment Program of the NMPOA cohort (Palmero et al., 2009). The seven questions of this instrument refer to family history features that have been associated with an increased likelihood of clinically significant $B R C A$ mutations and thus, these questions were designed primarily to identify patients at-risk for HBOC syndrome (Couch et al., 1997; Frank et al., 2002; Nelson et al., 2005; Shattuck-Eidens et al., 1997; Srivastava et al., 2001). In addition, a question about family history $(\mathrm{FH})$ of breast and/or colon cancer was included due to a previous suggestion of a higher than expected number of families with these tumors in cancer genetic clinics of Porto Alegre (Palmero et al., 2007). The questionnaire is presented in Table S1. Patients answering positively to at least one of the seven questions in the primary health care unit were referred to genetic risk assessment at NMPOA.

Genetic evaluation included medical and family histories recorded in detailed pedigrees with information traced as far backwards and laterally as possible, extending to paternal lines and including a minimum of three generations. Confirmation of the cancer FH was attempted in all cases and pathology and medical records, as well as death certificates, were obtained whenever possible upon specific consent from the patient and/or her family. Lifetime breast 
cancer risk estimates were obtained using the Claus, Gail, and Tyrer-Cuzick models. All pedigrees were reviewed by at least two clinical geneticists to assess presence of criteria for the diagnosis of LFS, LFL, HBCC, Cowden or other cancer predisposition syndromes. Patients fulfilling criteria for a breast cancer predisposition syndrome were candidates for the present study and offered genetic testing. For the clinical diagnosis of HBOC syndrome, the National Comprehensive Cancer Network ( $\mathrm{NCCN})$ and American Society of Clinical Oncology (ASCO) criteria were used (Ford et al., 1994) (NCCN, 2014). In addition, prior probabilities of carrying a $B R C A 1$ or $B R C A 2$ mutations were determined for each patient using mutation prevalence tables and the modified Couch mutation prediction model (Domchek et al., 2003; Frank et al., 2002). For LFS, the original criteria described by $\mathrm{Li}$ and Fraumeni (Li et al., 1988) were used; for LFL, pedigrees were classified according to the criteria of Birch (Birch et al., 1994) and Eeles (Eeles, 1995); for HBCC and Cowden's syndrome, the criteria described by (Meijers-Heijboer et al., 2003) and (Nelen et al., 1996), respectively, were used. Criteria to indicate genetic testing for $\mathrm{HBOC}$ were set so as not to miss any of the families at high risk for germline $B R C A 1$ and $B R C A 2$ mutations and included families fulfilling the ASCO criteria and/or who had a prior probability of mutation in a $B R C A$ gene of $30 \%$ or more (Domchek et al., 2003; Frank et al., 2002). Genetic testing included mutation analysis of one or more of the four main breast cancer predisposition genes (BRCA1, BRCA2, TP53, and CHEK2). Initially, the index case was approached and informed of the study. Invitation to participate was made directly to all cancer-affected index-cases. In those unaffected by cancer an attempt was made to invite at-risk, cancer affected relatives. Blood samples were obtained from cancer-affected women and/or their family members after informed consent, depending on accessibility of individuals and willingness to participate in the study. The study was approved by the Institutional Review Board of the participating centers.

\section{Screening for germline mutations}

DNA samples were obtained from peripheral blood, using a commercial DNA extraction kit, Gentra Puregene Blood kit, according manufacturer's instructions (Qiagen, Valencia, CA, USA). All DNA samples were screened for $B R C A 1 / 2$ and TP53 mutations using Denaturing High Performance Liquid Chromatography (DHPLC) or High Resolution Melting (HRM), and samples showing variants were submitted to Sanger sequencing.

\section{BRCA1/BRCA2 genes}

All samples were amplified by PCR reactions using oligonucleotide primers and corresponding annealing temperatures previously described in the literature (Friedman et al., 1997; Friedman et al., 1994). Mutation screening by
DHPLC was carried out using a WAVE MD 4000 DNA Fragment Analysis System equipped with a DNASep Cartridge (Transgenomic Inc., Omaha NE, USA) as described elsewhere (Fackenthal et al., 2005). The HRM curve analysis was performed in a LightScanner instrument (Idaho Tecnology Inc.) using the Light Scanner Mastermix with LCGreen dye (Idaho Tecnology Inc.). Heterozygous profiles were identified by visual inspection of the chromatograms/melting curves and putative sequence variants were re-analyzed by bi-directional sequencing on a MegaBACE 1000 (Amersham Biosciences, Buckinghamshire, UK) or an ABI-PRISM 3100 Genetic Analyzer (Applied Biosystems, Foster City, USA) using an independent PCR product. Sequence alterations were classified based on data available in the Breast Cancer Information Core (BIC, 2014), ClinVar (Landrum et al., 2014), Universal Mutation database - UMD (Caputo et al., 2012) and AlignGVGD (Tavtigian et al., 2006). New or pathogenic mutations were also searched in The Human Gene Mutation Database (HGMD, 2014,) and LOVD (Vallée et al., 2012). All the 18 HBOC families were screened for BRCA1 genomic rearrangements and 10 of these families were screened for $B R C A 2$ genomic rearrangements using Multiplex Ligation-dependent Probe Amplification (MLPA) methodology using the SALSA P002B BRCA1 and SALSA P045 BRCA2 MLPA probe mix assays (MRC-Holland, Amsterdam, The Netherlands) as recommended by the manufacturer (MRC-Holland) and information on copy number was extracted with Coffalyser V9.4 Software (MRC-Holland). All analyses were performed in duplicate and in at least two independent experiments.

\section{TP53 gene}

Patients fulfilling Li-Fraumeni and Li-Fraumeni-like syndrome criteria (Birch et al., 1994; Eeles, 1995; Li et al., 1988) were screened for TP53 germline mutations as follows: exons 2-11 were screened by HRM (as described by (Garritano et al., 2009) followed by bi-directional sequencing of altered regions. Sequence variations were classified according to data submitted to the TP53 database at the International Agency for Research on Cancer - IARC version R17 (Petitjean et al., 2007). All possible deleterious mutations were confirmed by a second and independent analysis.

\section{CHEK2 gene}

Families with a history of breast and colorectal cancer consistent with HBCC syndrome were screened for a specific CHEK2 mutation (1100delC), located in exon 10 by PCR amplification followed by direct sequencing. To ensure amplification of the functional copy of CHEK2 and exclusion of CHEK2 pseudogenes, a strategy of long-range PCR amplifications with primers designed outside the pseudogene sequences was used as described by (Vahteristo et al., 2001). 


\section{Results}

\section{Sample characteristics}

Of all 9,234 women included in the NMPOA cohort (Porto Alegre, Brazil), 1,286 (13.9\%) answered positively to at least one of the seven questions about FH. Those above 18 years $(n=1,247)$ were invited for GCRA. Of the 1,247 patients referred to GCRA, 902 (72.3\%) effectively participated in the assessment and of these, 214 (23.7\%) women from 183 families fulfilled criteria for one or more of the breast cancer predisposition syndromes (BCPS) considered in our study: 65 fulfilled criteria for HBOC, 122 for LFL and 22 for HBCC syndromes.

None of the patients assessed reported a personal and/or family history suggestive of classic Li-Fraumeni and Cowden's Syndrome. Detailed information on study design, patient recruitment, and demographic data of the 902 patients seen for GCRA is described elsewhere (Palmero et al., 2009).

Of the 214 women with criteria for a BCPS, 64 (29.9\%; corresponding to 50 families) decided to continue with the genetic investigation and proceeded to germline mutation testing. An additional 54 cancer-unaffected and at-risk patients (25.2\%) attempted contact with their cancer-affected relatives to invite them for GCRA but they did not schedule an appointment. Among the 50 probands tested, the most frequent cancer site was breast, and as expected, the majority of these diagnoses were made before the age of 50 years. Only two probands were diagnosed with ovarian cancer (one HBOC and one LFL family). Moreover, six probands had colorectal cancer (3 LFL and 3 HBCC families). Ten of the 50 probands were cancer unaffected (from 7 LFL families and three from families with both HBOC and LFL criteria). However, four of them were supposedly obligate carriers by family history. Additional information on cancer site and phenotype among the 50 families studied is summarized in Tables 1 and 2. At least one tumor diagnosis was confirmed by pathology reports, medical records, or death certificates in 45/50 (90\%) families. However, confirmation of a sufficient number of cancer diagnoses to affirm with certainty the BCPS phenotype was only possible in 13 families (26\%). Due to the high frequency of breast cancer diagnoses in the 50 families studied, $14(28 \%)$ of them fulfilled criteria for more than one BCPS when testing was indicated and therefore, these families were screened for germline mutations in more than one predisposition gene. Thus,eight families were tested for $B R C A 1 / B R C A 2$ and TP53 germline mutations, two families for $B R C A 1 / B R C A 2$ and $C H E K 2$ mutations, three families for TP53 and CHEK2 mutations, and one family was screened for mutations in all four genes (BRCA1/BRCA2, CHEK2 and TP53). During the process of genetic testing, three families presented additional information of the presumed cancer diagnoses and one of the phenotypes was ex-

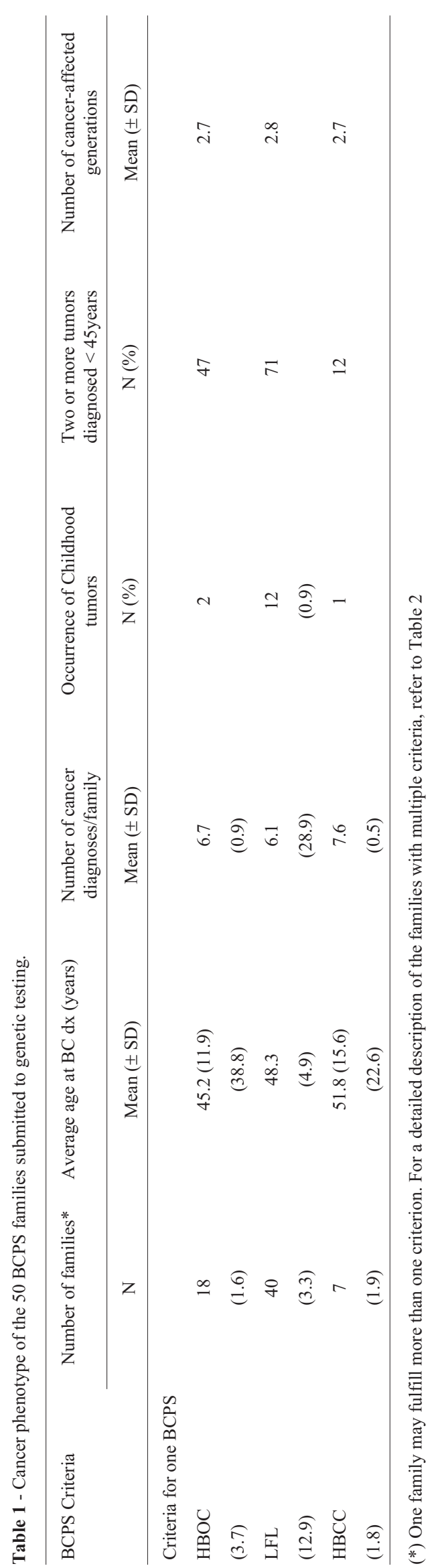




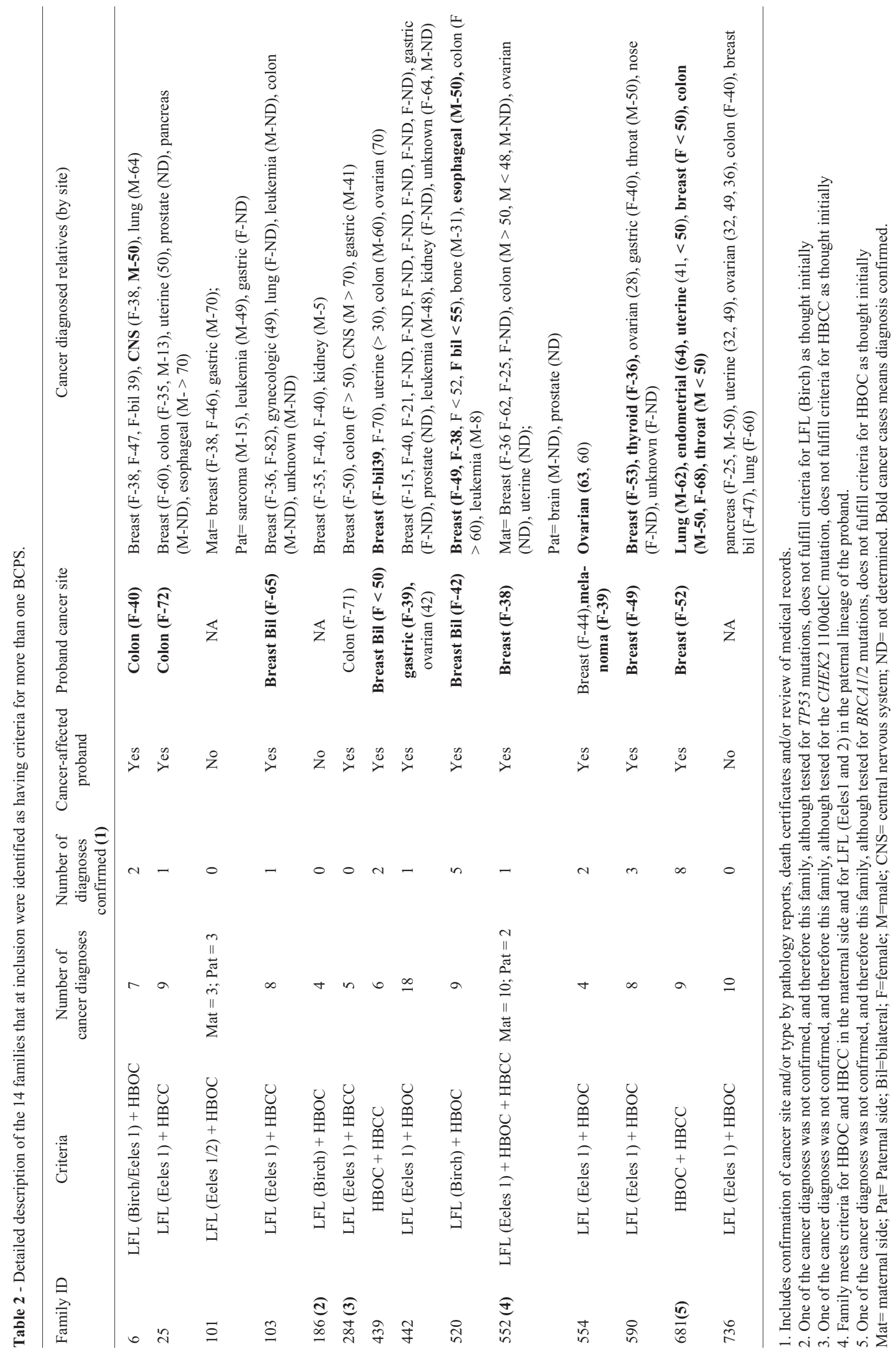


cluded (HBOC in family $681, \mathrm{HBCC}$ in family 284 , and LFL in two families, 163 and 186) (Table 2).

Mutation detection studies.

HBOC

Nineteen individuals from 18 families with HBOC criteria underwent genetic testing. After DHPLC or HRM screening, the PCR products showing variant or dubious profiles were sequenced for confirmation. A total of 183 of 646 (28.3\%) and 278 of 798 (34.8\%) BRCA1 and BRCA2 amplicons were sequenced, respectively. There was a complete agreement between the results from DHPLC and sequencing for both $B R C A$ genes.

Sequencing results were compared to data deposited in the BIC, ClinVar, UMD, HGMD and LOVD databases. We identified 12 and 31 sequence variants in $B R C A 1$ and $B R C A 2$, respectively (Table 3 ). Most of them were previously described and deposited in one or more databases as variants with no clinical significance. However, databases diverged about classification of some variants. In BRCA1, four variants were classified as variants of unknown significance (VUS) in at least one database, but none was classified as VUS in all three databases. In $B R C A 2$, two variants were consistently classified as VUS in all databases: c.9004G > A (p.E3002K) and c.9581C > A (p.P3194Q). However, in HGMD the variant p.E3002K is described as a deleterious mutation, and its pathogenicity was demonstrated (Biswas et al., 2012; Cote et al., 2012; Karchin et $a l ., 2008)$. The pedigree from this family can be seen in Figure 1. We also found three new variants in $B R C A 2$, not described in BIC, ClinVar, UMD, HGMD or LOVD: c.1402A > G (p.R468G), c.2842G > A (p.V948I) and c. $7017 \mathrm{G}>\mathrm{A}$ (p.K2339K). More detailed results can be found in Table 3. Screening for large gene rearrangements in all $18 \mathrm{HBOC}$ probands for $B R C A 1$ and in 10 for $B R C A 2$ did not show any detectable abnormalities.

\section{$L F L$}

One hundred twenty two families fulfilled the criteria for LFL syndrome (13.5\% of the entire initial sample), being 13 and 119 families fulfilling Birch and Eeles criteria, respectively. Ten families had both Birch and Eeles criteria for LFL. Of the 122 families, 40 probands (from 40 unrelated families) underwent genetic testing Twelve of these 40 families (30\%) also fulfilled criteria for at least on other BCPS (Table 2).

No deleterious mutation was found among the sequenced individuals, and the polymorphisms detected are shown in Table 4.

HBCC

Among the 183 families with a hereditary breast cancer phenotype, 22 fulfilled criteria for HBCC (MeijersHeijboer et al., 2003), but only seven of them underwent genetic testing. Interestingly, all of the seven families also fulfilled criteria for a BCPS other than $\mathrm{HBCC}$ at inclusion in the study. The common CHEK2 1100delC mutation was identified in one of these seven families (14.3\%) with multiple breast cancer diagnoses (proband had multiple breast cancers, first at age 52), colorectal cancer (ages 50 and 68 years), lung cancer and endometrial cancer (two cases) (Figure 2).

\section{Discussion}

The identification and characterization of genetic alterations in families at high risk for breast cancer predisposition syndromes enables carriers to undertake individualized cancer screening and prevention strategies, thus increasing the likelihood of increased disease-free survival rates.

For HBOC, although we aimed at selecting patients at a somewhat higher prior probability of mutation than in most studies (average mutation probability between 20$30 \%$ using different criteria and prediction models) we identified a known deleterious germline mutation in only one of the 18 families studied. Using a strategy of screening for four common alterations in BRCA1 and BRCA2 (185delAG, 5382insC and exon 13 6kb duplication in BRCA1 and 6174delT in BRCA2), Gomes (Gomes et al., 2007) showed a mutation frequency of $2.3 \%$ of the 5382insC mutation in 402 Brazilian breast cancer patients unselected for family history. Although the average prior probability of mutation in their sample is not clear, one would expect that it was likely less (unselected sample) than the cutoff probability used for offering genetic testing in our report. In another Brazilian study that assessed BRCA1 mutation prevalence in a group of 47 women from Rio de Janeiro, Lourenço et al. (Lourenço JJ VF, 2004), using more strict inclusion criteria, found $7(15.0 \%)$ mutation carriers; again, 5382insC was one of the most common mutations encountered (4/7). Analyzing germline mutations in all coding regions of $B R C A 1$ and in common founder mutations in the BRCA2, CHEK2 and TP53 genes in a cohort of 106 high-risk HBOC patients, Felix et al. (Felix et al., 2014) found 10 mutation carriers, and of them 9 harbored mutations in BRCA1 (and none in BRCA2), performing a mutation frequency of $8,49 \%$. A recent study of our group accessed the prevalence of three founder mutations (BRCA1 c.68 69del, BRCA1 c.5266dupC - former named as $5382 \mathrm{insC}$, and BRCA2 c.5946del) commonly identified in Ashkenazi individuals in a sample of 137 non-Ashkenazi cancer-affected women from Rio de Janeiro and Porto Alegre (all of them fulfilled clinical criteria for HBOC). The only mutation found was BRCA1 c.5266dupC (5382insC), present in 7/137 women, a prevalence of $5.10 \%$ (Ewald et al., 2011). A posterior study also conducted in Porto Alegre evaluated the prevalence of three Ashkenazi founder mutations (BRCA1 185delAG, BRCA1 5382 insC and $B R C A 26174 \mathrm{delT}$ ) in a group of 255 Ashkenazi Jewish women, non selected for personal or familial 
Table 3 - $B R C A 1$ and $B R C A 2$ sequence variants identified in the 18 families fulfilling HBOC syndrome criteria.

\begin{tabular}{|c|c|c|c|c|c|c|c|}
\hline \multirow[b]{2}{*}{ Localization } & \multirow[b]{2}{*}{ Alteration* } & \multicolumn{6}{|c|}{ Classification } \\
\hline & & UMD & $\begin{array}{c}\text { BIC } \\
\text { (Clinical } \\
\text { impor- } \\
\text { tance) }\end{array}$ & ClinVar & $\begin{array}{c}\text { Align- } \\
\text { GVGD } \\
\text { score*** }\end{array}$ & $\begin{array}{c}\text { Families } \\
\text { with } \\
\text { variant } \\
\text { (N) }\end{array}$ & Detection method \\
\hline \multicolumn{8}{|l|}{ BRCA1 } \\
\hline Intron 7 & c. $442-34 \mathrm{C}>\mathrm{T}(\mathrm{IVS} 7-34 \mathrm{C}>\mathrm{T})$ & Polym. & No & ND & NA & 2 & DHPLC+Sequencing \\
\hline Intron 7 & c. $442-18 \mathrm{C}>\mathrm{T}(\mathrm{IVS} 7-18 \mathrm{C}>\mathrm{T})$ & VUS & ND & ND & NA & 5 & HRM+Sequencing \\
\hline Exon 11 & c.1067 A > G (p.Q356R) & Neutral & VUS & Conf. data**1 & $\mathrm{C} 0$ & 4 & HRM+Sequencing \\
\hline \multirow[t]{2}{*}{ Exon 11} & c.2082 C > T (p.S694S) & Neutral & VUS & $\mathrm{B} / \mathrm{LB}$ & NA & 8 & Direct Sequencing \\
\hline & & & & & & 7 & DHPLC+Sequencing \\
\hline \multirow[t]{2}{*}{ Exon 11} & c.2311 T > C (p.L771L) & Neutral & No & $\mathrm{B} / \mathrm{LB}$ & NA & 8 & Direct Sequencing \\
\hline & & & & & & 2 & DHPLC+Sequencing \\
\hline \multirow[t]{2}{*}{ Exon 11} & c.2612 C > T (p.P871L) & Neutral & No & $\mathrm{B} / \mathrm{LB}$ & $\mathrm{C} 0$ & 7 & Direct Sequencing \\
\hline & & & & & & 8 & DHPLC+Sequencing \\
\hline \multirow[t]{2}{*}{ Exon 11} & c.3113 A > G (p.E1038G) & Neutral & No & $\mathrm{B} / \mathrm{LB}$ & $\mathrm{C} 0$ & 9 & Direct Sequencing \\
\hline & & & & & & 5 & DHPLC+Sequencing \\
\hline Exon 11 & c. 3119 G > A (p.S1040N) & Neutral & VUS & Conf. data**2 & $\mathrm{C} 0$ & 2 & Direct Sequencing \\
\hline \multirow[t]{2}{*}{ Exon 11} & c.3548 A > G (p.K1183R) & Neutral & No & $\mathrm{B} / \mathrm{LB}$ & $\mathrm{C} 0$ & 9 & Direct Sequencing \\
\hline & & & & & & 7 & DHPLC+Sequencing \\
\hline Exon 13 & c.4308 T > C (p.S1436S) & Neutral & No & $\mathrm{B} / \mathrm{LB}$ & NA & 10 & Direct Sequencing \\
\hline Exon 16 & c.4837A > G (p.S1613G) & Neutral & No & $\mathrm{B} / \mathrm{LB}$ & $\mathrm{C} 0$ & 10 & DHPLC + Sequencing \\
\hline Intron 18 & c. $5152+66 \mathrm{G}>\mathrm{A}(\mathrm{IVS} 18+66 \mathrm{G}>\mathrm{A})$ & Neutral & No & ND & NA & 13 & DHPLC+Sequencing \\
\hline \multicolumn{8}{|l|}{ BRCA2 } \\
\hline 5'UTR & c. $-26 \mathrm{G}>\mathrm{A}$ & Neutral & No & $\mathrm{B} / \mathrm{LB}$ & NA & 9 & DHPLC+Sequencing \\
\hline Intron 4 & c. $426-89 \mathrm{~T}>\mathrm{C}(\mathrm{IVS} 4-89 \mathrm{~T}>\mathrm{C})$ & Neutral & No & VUS & NA & 10 & DHPLC+Sequencing \\
\hline Intron 4 & c. $425+67 \mathrm{~A}>\mathrm{C}(\mathrm{IVS} 6+67 \mathrm{~A}>\mathrm{C})$ & Neutral & No & VUS & NA & 7 & HRM+Sequencing \\
\hline Intron 6 & c. $516+14 \mathrm{C}>\mathrm{T}(\mathrm{IVS} 6+14 \mathrm{C}>\mathrm{T})$ & Lik. Neut. & ND & $\mathrm{B} / \mathrm{LB}$ & NA & 1 & HRM+Sequencing \\
\hline \multirow[t]{2}{*}{ Exon 10} & c. $865 \mathrm{~A}>\mathrm{C}(\mathrm{p} . \mathrm{N} 289 \mathrm{H})$ & Neutral & No & $\mathrm{B} / \mathrm{LB}$ & $\mathrm{C} 0$ & 3 & HRM+Sequencing \\
\hline & & & & & & 5 & DHPLC+Sequencing \\
\hline \multirow[t]{2}{*}{ Exon 10} & c. $1114 \mathrm{~A}>\mathrm{C}(\mathrm{p} . \mathrm{H} 372 \mathrm{~N})$ & Neutral & No & Conf. data $* *^{3}$ & $\mathrm{C} 0$ & 6 & HRM+Sequencing \\
\hline & & & & & & 14 & HRM \\
\hline \multirow[t]{2}{*}{ Exon 10} & c. $1365 \mathrm{~A}>\mathrm{G}(\mathrm{p} . \mathrm{S} 455 \mathrm{~S})$ & Neutral & No & $\mathrm{B} / \mathrm{LB}$ & NA & 8 & HRM+Sequencing \\
\hline & & & & & & 1 & HRM \\
\hline \multirow[t]{2}{*}{ Exon 10} & c.1402A > G (p.R468G) & ND & ND & ND & $\mathrm{C} 0$ & 1 & HRM+Sequencing \\
\hline & & & & & & 3 & HRM \\
\hline Intron 10 & c. $1910-74 \mathrm{~T}>\mathrm{C}(\mathrm{IVS} 10-74 \mathrm{~T}>\mathrm{C})$ & Polym. & No & ND & NA & 9 & DHPLC+Sequencing \\
\hline \multirow[t]{2}{*}{ Exon 11} & c.2229T > C (p.H743H) & Neutral & No & $\mathrm{B} / \mathrm{LB}$ & NA & 4 & Direct sequencing \\
\hline & & & & & & 1 & DHPLC+Sequencing \\
\hline Exon 11 & c. $2803 \mathrm{G}>\mathrm{A}(\mathrm{p} . \mathrm{D} 935 \mathrm{~N})$ & Neutral & No & $\mathrm{B} / \mathrm{LB}$ & $\mathrm{C} 0$ & 1 & HRM+Sequencing \\
\hline Exon 11 & c.2842G > A (p.V948I) & ND & ND & ND & $\mathrm{CO}$ & 1 & HRM+Sequencing \\
\hline Exon 11 & c.2971A > G (p.N991D) & Neutral & No & $\mathrm{B} / \mathrm{LB}$ & $\mathrm{C} 0$ & 6 & HRM+Sequencing \\
\hline Exon 11 & c. $3396 \mathrm{~A}>\mathrm{G}$ (p.K1132K) & Neutral & No & $\mathrm{B} / \mathrm{LB}$ & NA & 20 & Direct sequencing \\
\hline Exon 11 & c.3807T > C (p.V1269V) & Neutral & No & $\mathrm{B} / \mathrm{LB}$ & NA & 11 & HRM+Sequencing \\
\hline Exon 11 & c.5096A > G (p.D1699G) & $\mathrm{ND}$ & VUS & VUS & $\mathrm{C} 0$ & 1 & HRM+Sequencing \\
\hline Exon 11 & c.5199C > T (p.S1733S) & Neutral & No & $\mathrm{B} / \mathrm{LB}$ & NA & 1 & HRM+Sequencing \\
\hline Exon 11 & c.5418A > G (p.E1806E) & Lik. Neut. & No & $\mathrm{B} / \mathrm{LB}$ & NA & 1 & HRM+Sequencing \\
\hline Exon 11 & c. $5744 \mathrm{C}>\mathrm{T}(\mathrm{p} . \mathrm{T} 1915 \mathrm{M})$ & Neutral & No & Conf. data**4 & $\mathrm{C} 0$ & 3 & HRM+Sequencing \\
\hline
\end{tabular}


Table 3 (cont.)

\begin{tabular}{|c|c|c|c|c|c|c|c|}
\hline Exon 11 & c.6323G > A (p.R2108H) & Neutral & VUS & Conf. data**5 & $\mathrm{C} 0$ & 1 & HRM+Sequencing \\
\hline Intron 13 & c. $7008-62 \mathrm{~A}>\mathrm{G}(\mathrm{IVS} 13-62 \mathrm{~A}>\mathrm{G})$ & Neutral & VUS & Conf.data**6 & NA & 1 & Direct sequencing \\
\hline Exon 14 & c.7017G > A (p.K2339K) & ND & ND & ND & NA & 1 & Direct sequencing \\
\hline Exon 14 & c.7242A > G (p.S2414S) & Neutral & No & $\mathrm{B} / \mathrm{LB}$ & NA & 10 & HRM+Sequencing \\
\hline Intron 16 & c.7806-14T > C (IVS16-14T > C) & Neutral & VUS & $\mathrm{B} / \mathrm{LB}$ & NA & 15 & DHPLC+Sequencing \\
\hline Exon 18 & c. $8171 \mathrm{G}>\mathrm{T}(\mathrm{p} . \mathrm{G} 2724 \mathrm{~V})$ & ND & VUS & ND & $\mathrm{C} 15$ & 6 & DHPLC+Sequencing \\
\hline Exon 20 & c.8567A > G (p.E2856A) & ND & No & ND & $\mathrm{C} 0$ & 2 & DHPLC+Sequencing \\
\hline Exon 22 & c. $8850 \mathrm{G}>\mathrm{T}(\mathrm{p} . \mathrm{K} 2950 \mathrm{~N})$ & Neutral & VUS & Conf. data**7 & $\mathrm{C} 35$ & 1 & HRM+Sequencing \\
\hline Exon 22 & c.8851G > A (p.A2951T) & Neutral & No & $\mathrm{B} / \mathrm{LB}$ & $\mathrm{C} 0$ & 3 & HRM+Sequencing \\
\hline Exon 23 & c. $9004 \mathrm{G}>\mathrm{A}(\mathrm{p} . \mathrm{E} 3002 \mathrm{~K})$ & VUS & VUS & Conf. data**8 & C55 & 1 & HRM+Sequencing \\
\hline Exon 26 & c.9581C > A (p.P3194Q) & VUS & VUS & Conf. data**7 & $\mathrm{C} 0$ & 1 & HRM+Sequencing \\
\hline Exon 27 & c. $10234 \mathrm{~A}>\mathrm{G}(\mathrm{p} . \mathrm{I} 3412 \mathrm{~V})$ & Neutral & No & Conf. data**8 & $\mathrm{C} 0$ & 2 & HRM+Sequencing \\
\hline
\end{tabular}

*Nomenclature following HGVS recommendations

$* *$ Conf. data $=$ Conflicting data from submitter (evaluated in July 2014). The superscript numbers correspond to the number between brackets. The number between parentheses means how many registries were made in each category. [1]: Benign (6), Likely benign (1), Uncertain significance (1); [2]: Benign (6), Likely benign (1), Pathogenic (1), Uncertain significance (1); [3] Benign (3), Pathogenic (1); [4] Benign (6), Likely benign (1), Uncertain significance (1); [5] Benign (4), Likely benign (1), Uncertain significance (1); [6] Benign (2), Uncertain significance (1); [7] Benign (2), Uncertain significance (1); [8] Likely pathogenic (1), Pathogenic (1) Uncertain significance (1); [9] Benign (1), Likeli benign (1), Uncertain significance (2); [10] Benign (5), Uncertain significance (1).

*** Align-GVGD score combines the biophysical characteristics of amino acids and protein multiple sequence alignments to predict where missense substitutions fall in a spectrum from enriched deleterious ( 655 , most likely to interfere with function) to enriched neutral (C0, least likely).

Bold variants highlight the new ones described in this study.

$\mathbf{B} / \mathbf{B L}=$ Benign $/$ Likely benign; Lik. Net. $=$ Likely neutral; NA $=$ Not applicable; ND $=$ Not described; Polym. $=$ Polymorphism; VUS $=$ Variant of unknown significance;

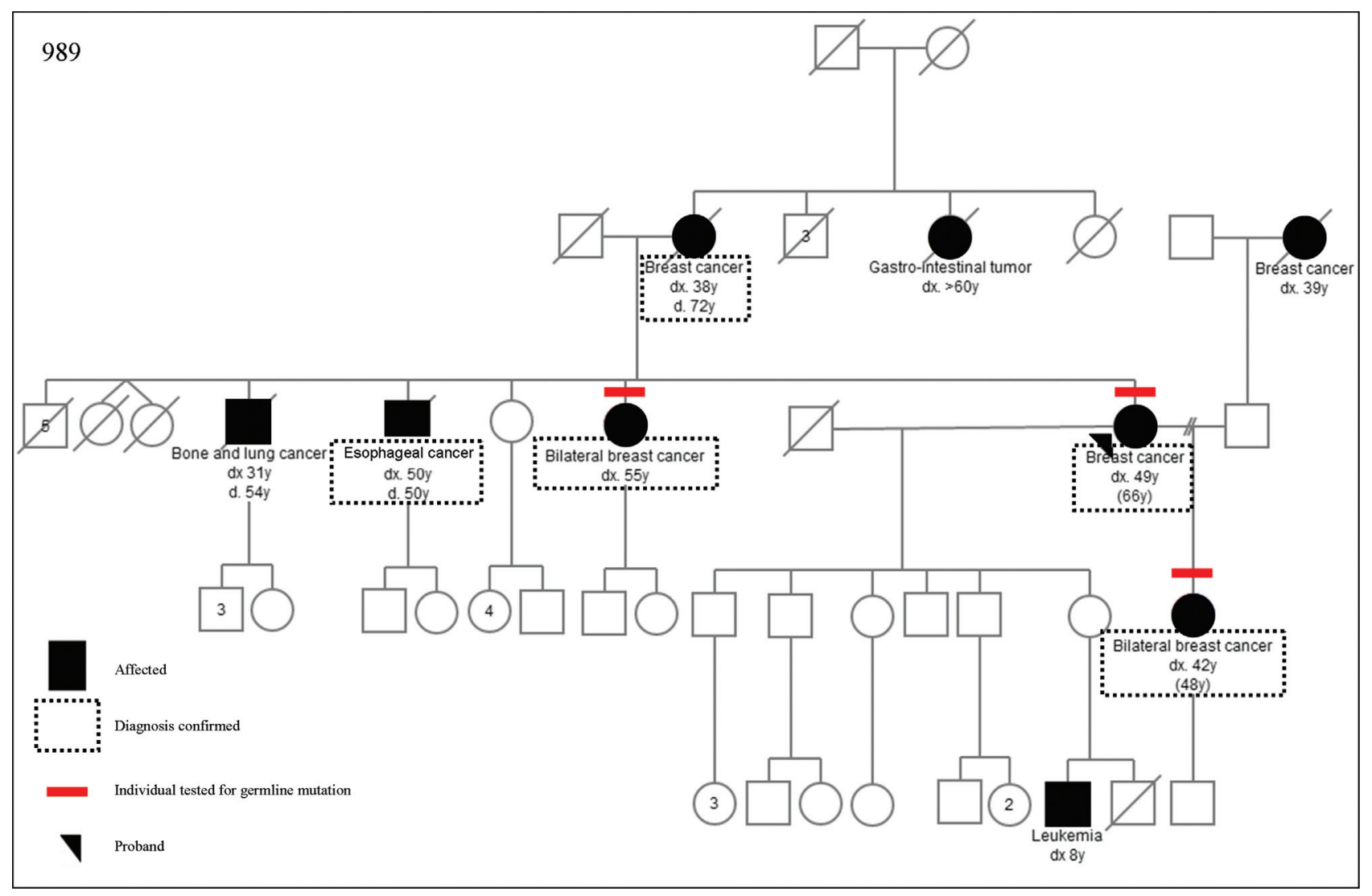

Figure 1 - Pedigree of a family with p.E3002K mutation in $B R C A 2$ gene. 
Table 4 - TP53 sequence variants identified in the 40 families fulfilling LFL syndrome criteria.

\begin{tabular}{lcccc}
\hline Localization & rs number & Alteration & ClinVar & Number of affected families \\
\hline Intron 2 & rs1642785 & c.74+38C $>$ G (IVS2+38C $>$ G, PIN2) & Benign/Likely benign & 30 \\
Intron 3 & rs17878362 & $\begin{array}{r}\text { c.96+25_96+40ACCTGGAGGGCTGGG } \\
\text { (IVS3+24insACCTGGAGGGCTGGGG, PIN3) }\end{array}$ & Benign/Likely benign & 16 \\
Exon 4 & rs1800370 & c.108G $>$ A (p.P36P) & Benign/Likely benign & 2 \\
Exon 4 & rs1042522 & c.215CG (p.P72R, PEX4) & Conflicting data* & 34 \\
Intron 7 & rs12951053 & c.782+92T $>$ G (IVS7+92T $>$ G) & ND & 3 \\
Intron 9 & rs1800899 & c.993+12T $>$ C (IVS9+12T $>$ C) & Benign/Likely benign & 1 \\
\hline
\end{tabular}

*Conflicting data $=$ Conflicting data from submitter (evaluated in July 2014). The number between parentheses means how many registries were made in each category: Benign(4); Uncertain significance (1).

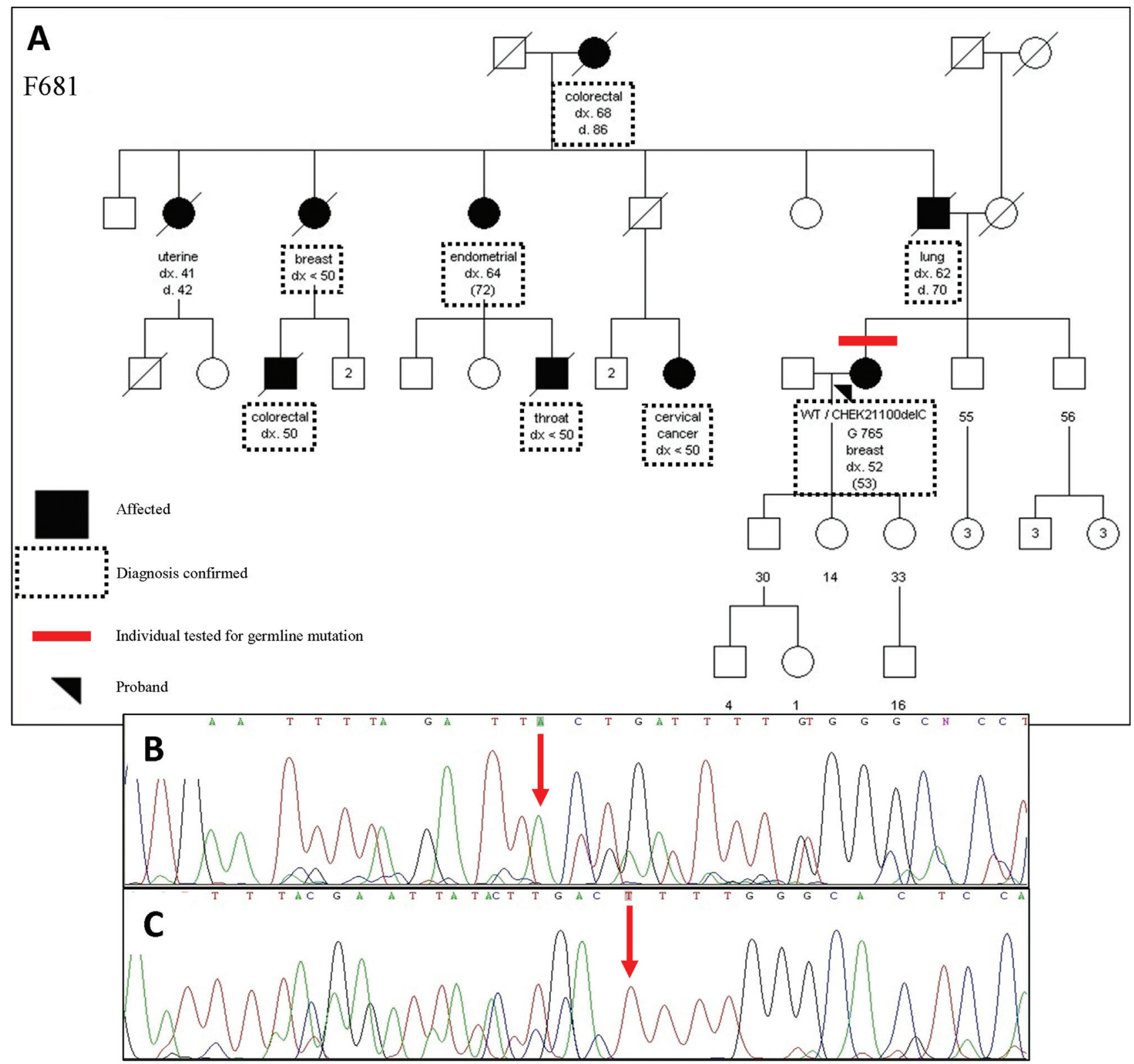

Figure 2 - CHEK2 1100delC mutation family. Pedigree (A), forward (B) and reverse (C) sequencing of germline DNA. WT=wild type; $\mathrm{dx}=$ age at diagnosis; $d=a g e$ of death; red arrows indicate the last readable base. 
cancer history, and found a carrier frequency of $2 / 255$ for 185 delAG $(0,78 \%), 1 / 255$ for 6174 delT $(0,4 \%)$ and no mutated alleles for $5382 \mathrm{insC}$, reveling a carrier frequency lower than expected for this ethnic group (Dillenburg et al., 2012).

Indeed, $B R C A$ mutation prevalence is probably heterogeneous, not only depending on criteria adopted for inclusion in a given study, but also related to testing methodology and specific features of different populations. For example, in a Finnish study of 128 HBOC patients, (Laurila et al., 2005) did not identify any BRCA1 mutation after sequencing the entire coding region of the gene. Finally, the effects of a small sample size and less than optimal confirmation of the cancer diagnoses in many of the families in our cohort must also be considered.

The negative findings of gene rearrangements in $B R C A 1$ and $B R C A 2$ could also be related to small sample size and, again, to the large variability of rearrangement prevalence. One complicating factor is that the knowledge about prevalence of such rearrangements in South American HBOC patients is limited and studies in other populations report a highly variable prevalence of such rearrangements. A Brazilian study conducted with 120 women fulfilling criteria for $\mathrm{HBOC}$ and screened for mutations, CNVs and rearrangements in $B R C A$ and other genes found rearrangements of $B R C A 1$ in only two cases (exon 24 amplification and exon 16-17 deletion) (Silva et al., 2014). In the Dutch, for example, large genomic rearrangements constitute $36 \%$ of the mutations detected in BRCA1 (PetrijBosch et al., 1997).

In spite of the large number of sequence variants identified in the BRCA1/BRCA2 genes worldwide, many of them are still classified as VUS, and the available databases diverge about classification of variants. In this study, we found four $B R C A 1$ variants classified as VUS in at least one database, and two $B R C A 2$ variants that were consistently classified as VUS in all three analyzed databases, although one of them is, indeed, pathogenic (E3002K) (Biswas et al., 2012; Cote et al., 2012; Karchin et al., 2008). Although the results are conflicting between the databases, functional studies done by Biswas et al. (2012) point to the fact that the mutation p.E3002K negatively impacts ssDNA binding and function, resulting in a deleterious phenotype. The findings on the likely pathogenicity of this mutation were corroborated by work published by Cote et al. (2012) in a recent study of 58 French Canadian families with breast and/or ovarian cancer and 960 cases not selected for family history of cancer, which found this variant in seven of the 58 families with a family history of cancer and in none of those not selected for family history. Additionally the AlignGVGD score for pathogenicity for this specific mutation is $\mathrm{C} 55$, pointing to a possibly/probably pathogenic alteration. Three novel sequence variants were found in $B R C A 2$, two of them in the same individual. Further characterization of these novel variants is imperative and is un- derway. All efforts will be made to further characterize variants of unknown significance, especially if they were not described previously.

The finding of a high number of pedigrees suggestive of the LFL phenotype in our sample was somewhat surprising. First, because the questionnaire used to screen women from the general population for GCRA, was originally designed to identify the HBOC phenotype, and second because Li-Fraumeni syndrome and its variants have not been considered common cancer predisposition syndromes in most countries. However, Eeles I criteria, the only ones present in the majority of the 40 probands studied, are very relaxed and mutation prevalence in these families has been described as low (under 10\%), which is in agreement with the absence of deleterious TP53 mutations identified in our study. Interestingly, in other published mutation study of Brazilian LFL families (including 10 families from the State of Rio Grande do Sul), the mutation prevalence for LFL Eeles 1 and Birch families was much higher (23.1\% and $61.5 \%$, respectively). Again, our findings may be related to relatively small sample sizes and to the presence of lower-risk LFL families, some of them not having a sufficient number of cancer diagnoses confirmed to allow certainty about the BCPS phenotype. Finally, screening for the common CHEK2-1100delC mutation in seven HBCC families resulted in the identification of one mutation-positive family corresponding to a mutation prevalence of about $14 \%$, (comparable to the $18 \%$ previously described in the literature) (Petrij-Bosch et al., 1997). With the small sample size analyzed, these results could merely be related to chance, however they go along with other previous observations of a higher than expected number of colon cancers in the families breast-cancer affected women undergoing GCRA (Palmero et al., 2009).

Two major limitations can be identified in our study. First, the relatively small sample size, which is not entirely unexpected. The limited acceptance of genetic testing that we faced throughout this study may be explained by cultural aspects of the population, low literacy of the majority of women counseled and this in turn could be associated with limited understanding of the benefits and implications of testing. Study design may also have influenced genetic testing acceptance. The women included in this study were recruited from their primary health care units and were not originally concerned about their genetic risk for cancer; or, if they were concerned, they did not seek genetic counseling directly. Furthermore, since our cohort was originated from a population-based sample, some of our probands were cancer-unaffected individuals from at-risk families for whom genetic testing required participation of at least one willing and alive cancer-affected relative. Another potential concern is that only a proportion of cancers in probands and/or relatives were confirmed, and therefore, there may be misclassifications of cancer site, tumor type as well as age at tumor diagnosis. Confirmation of cancer diagno- 
ses in relatives, often distant ones, is usually challenging and in this population it may be particularly difficult, since many of them have lost contact with their families. All of these factors together may also contribute to poor understanding about increased risk and the existence and benefits of risk reduction strategies and consequent reduced motivation for genetic testing. In spite of the use of relatively strict inclusion criteria for testing of some BCPS (such as HBOC) and less strict criteria for others (LFL) and the comprehensive testing methodology used, the high risk posed to most of the families described here remains unexplained. Even considering the limitations highlighted before, this study raises several questions about the importance of genetic factors in determining the high breast cancer incidence and mortality rates in Southern Brazil and the acceptability of genetic testing in this population. In order to validate the low prevalence of germline mutations found in this work, a larger cohort should be analyzed. If indeed it is, we may have to revise criteria for genetic testing in this population and thoroughly investigate the contribution of different and/or novel high penetrance genes or the influence of multiple, more prevalent genetic variants of lower penetrance.

\section{Acknowledgments}

The Núcleo Mama (NMPOA) Cohort, from which the patients derive, is maintained by Associação Hospitalar Moinhos de Vento, in a partnership with Instituto da Mama do Rio Grande do Sul and the Municipal Health Agency from Porto Alegre. The authors are indebted to Danielle Renzoni da Cunha, Ghyslaine Martel-Planche, Matias Eliseo Melendez, Patricia Schneider, Hermides Pinto Junior and Andre Muller for their expert technical assistance; to Karen Barbosa and Diego Pasetto for their assistance with data managing, patient recruitment and pedigree organization and to Ana Cecília Mano de Azevedo, Ademar Bedin Júnior, Luciane Poletto Antunes, Juliana Zignani, Fávio Marcel Telis Gonzalez, Luciano Artico, and the NMPOA team for their help with the recruitment, evaluation and follow-up of the patients included in this study. This study was supported by a grant from Susan G. Komen for the Cure (POP0403033), and in part by grants from Fundo de Incentivo à Pesquisa - FIPE, Hospital de Clínicas de Porto Alegre (\# 04-170) and Coordenação de Aperfeiçoamento de Pessoal de Nível Superior (CAPES - PRODOC grant number 00202/03-7). EI Palmero was supported in part by grants from The International Agency for Research in Cancer (IARC) and CNPq (process number 203732/2005-7).

\section{References}

Antoniou AC, Pharoah PD, Easton DF and Evans DG (2006) BRCA1 and BRCA2 cancer risks. J Clin Oncol 24:33123313; author reply 3313-3314.

Birch JM, Hartley AL, Tricker KJ, Prosser J, Condie A, Kelsey AM, Harris M, Jones PH, Binchy A and Crowther D (1994)
Prevalence and diversity of constitutional mutations in the p53 gene among 21 Li-Fraumeni families. Cancer Res 54:1298-1304.

Biswas K, Das R, Eggington JM, Qiao H, North SL, Stauffer S, Burkett SS, Martin BK, Southon E, Sizemore SC, et al. (2012) Functional evaluation of BRCA2 variants mapping to the PALB2-binding and C-terminal DNA-binding domains using a mouse ES cell-based assay. Hum Mol Genet 21:3993-4006.

Caleffi M, Ribeiro RA, Bedin Jr. AJ, Viegas-Butzke JM, Baldisserotto FD, Skonieski GP, Giacomazzi J, Camey SA and Ashton-Prolla P (2010) Adherence to a breast cancer screening program and its predictors in underserved women in southern Brazil. Cancer Epidemiol Biomarkers perv 19:2673-2679.

Caputo S, Benboudjema L, Sinilnikova O, Rouleau E, Béroud C, Lidereau R and French BRCA GGC Consortium (2012) Description and analysis of genetic variants in French hereditary breast and ovarian cancer families recorded in the UMD-BRCA1/BRCA2 databases. Nucleic Acids Res 40:D992-1002.

Carraro DM, Koike Folgueira MA, Garcia Lisboa BC, Ribeiro Olivieri EH, Vitorino Krepischi AC, de Carvalho AF, de Carvalho Mota LD, Puga RD, do Socorro Maciel M, Michelli RA, et al. (2013) Comprehensive analysis of BRCA1, BRCA2 and TP53 germline mutation and tumor characterization: A portrait of early-onset breast cancer in Brazil. PLoS One 8:e57581.

Cass I, Baldwin RL, Varkey T, Moslehi R, Narod SA and Karlan BY (2003) Improved survival in women with BRCA-associated ovarian carcinoma. Cancer 97:2187-2195.

Cote S, Arcand SL, Royer R, Nolet S, Mes-Masson AM, Ghadirian P, Foulkes WD, Tischkowitz M, Narod SA, Provencher D, et al. (2012) The BRCA2 c.9004G > A (E2002K) [corrected] variant is likely pathogenic and recurs in breast and/or ovarian cancer families of French Canadian descent. Breast Cancer Res Treat 131:333-340.

Couch FJ, DeShano ML, Blackwood MA, Calzone K, Stopfer J, Campeau L, Ganguly A, Rebbeck T and Weber BL (1997) BRCA1 mutations in women attending clinics that evaluate the risk of breast cancer. N Engl J Med 336:1409-1415.

Dillenburg CV, Bandeira IC, Tubino TV, Rossato LG, Dias ES, Bittelbrunn AC and Leistner-Segal S (2012) Prevalence of 185 delAG and 5382insC mutations in BRCA1, and 6174delT in BRCA2 in women of Ashkenazi Jewish origin in southern Brazil. Genet Mol Biol 35:599-602.

Domchek SM, Eisen A, Calzone K, Stopfer J, Blackwood A and Weber BL (2003) Application of breast cancer risk prediction models in clinical practice. J Clin Oncol 21:593-601.

Eeles RA (1995) Germline mutations in the TP53 gene. Cancer Surv 25:101-124.

Euhus DM and Robinson L (2013) Genetic predisposition syndromes and their management. Surg Clin North Am 93:341-362.

Ewald IP, Izetti P, Vargas FR, Moreira MA, Moreira AS, Moreira-Filho CA, Cunha DR, Hamaguchi S, Camey SA, Schmidt A., et al. (2011) Prevalence of the BRCA1 founder mutation c.5266dupin Brazilian individuals at-risk for the hereditary breast and ovarian cancer syndrome. Hered Cancer Clin Pract 9:12. 
Fackenthal DL, Chen PX and Das S (2005) Denaturing highperformance liquid chromatography for mutation detection and genotyping. Methods Mol Biol 311:73-96.

Felix GE, Abe-Sandes C, Machado-Lopes TM, Bomfim TF, Guindalini RS, Santos VC, Meyer L, Oliveira PC, Claudio Neiva J, Meyer R, et al. (2014) Germline mutations in BRCA1, BRCA2, CHEK2 and TP53 in patients at high-risk for HBOC: Characterizing a Northeast Brazilian Population. Hum Genome Var 1:14012.

Ford D, Easton DF, Bishop DT, Narod SA and Goldgar DE (1994) Risks of cancer in BRCA1-mutation carriers. Breast Cancer Linkage Consortium. Lancet 343:692-695.

Frank TS, Deffenbaugh AM, Reid JE, Hulick M, Ward BE, Lingenfelter B, Gumpper KL, Scholl T, Tavtigian SV, Pruss DR, et al. (2002) Clinical characteristics of individuals with germline mutations in BRCA1 and BRCA2: Analysis of 10,000 individuals. J Clin Oncol 20:1480-1490.

Friedman LS, Gayther SA, Kurosaki T, Gordon D, Noble B, Casey G, Ponder BA and Anton-Culver H (1997) Mutation analysis of BRCA1 and BRCA2 in a male breast cancer population. Am J Hum Genet 60:313-319.

Friedman LS, Ostermeyer EA, Szabo CI, Dowd P, Lynch ED, Rowell SE and King MC (1994) Confirmation of BRCA1 by analysis of germline mutations linked to breast and ovarian cancer in ten families. Nat Genet 8:399-404.

Garritano S, Gemignani F, Voegele C, Nguyen-Dumont T, Le Calvez-Kelm F, De Silva D, Lesueur F, Landi S and Tavtigian SV (2009) Determining the effectiveness of High Resolution Melting analysis for SNP genotyping and mutation scanning at the TP53 locus. BMC Genet 10:5.

Gomes MC, Costa MM, Borojevic R, Monteiro AN, Vieira R, Koifman S, Koifman RJ, Li S, Royer R. Zhang S, et al. (2007) Prevalence of BRCA1 and BRCA2 mutations in breast cancer patients from Brazil. Breast Cancer Res Treat 103:349-353.

Goss PE, Lee BL, Badovinac-Crnjevic T, Strasser-Weippl K, Chavarri-Guerra Y, St Louis J, Villarreal-Garza C, UngerSaldaña K, Ferreyra M, Debiasi M, et al. (2013) Planning cancer control in Latin America and the Caribbean. Lancet Oncol 14:391-436.

Gutiérrez-Enríquez S, de la Hoya M, Martínez-Bouzas C, Sanchez de Abajo A, Ramón y Cajal T, Llort G, Blanco I, Beristain E, Díaz-Rubio E, Alonso C, et al. (2007) Screening for large rearrangements of the BRCA2 gene in Spanish families with breast/ovarian cancer. Breast Cancer Res Treat 103:103-107.

Hendrickson BC, Judkins T, Ward BD, Eliason K, Deffenbaugh AE, Burbidge LA, Pyne K, Leclair B, Ward BE and Scholl T (2005) Prevalence of five previously reported and recurrent BRCA1 genetic rearrangement mutations in 20,000 patients from hereditary breast/ovarian cancer families. Genes Chromosomes Cancer 43:309-313.

Karchin R, Agarwal M, Sali A, Couch F and Beattie MS (2008) Classifying Variants of Undetermined Significance in BRCA2 with protein likelihood ratios. Cancer Inform 6:203-216.

King MC, Marks JH, Mandell JB and Group, New York Breast Cancer Study (2003) Breast and ovarian cancer risks due to inherited mutations in BRCA1 and BRCA2. Science 302:643-646.
Landrum MJ, Lee JM, Riley GR, Jang W, Rubinstein WS, Church DM and Maglott DR (2014) ClinVar: Public archive of relationships among sequence variation and human phenotype. Nucleic Acids Res 42:D980-985.

Laurila E, Syrjäkoski K, Holli K, Kallioniemi A and Karhu R (2005) Search for large genomic alterations of the BRCA1 gene in a Finnish population. Cancer Genet Cytogenet 163:57-61.

Li FP, Fraumeni JF, Mulvihill JJ, Blattner WA, Dreyfus MG, Tucker MA and Miller RW (1988) A cancer family syndrome in twenty-four kindreds. Cancer Res 48:5358-5362.

Lourenço JJ, Vargas FR, Bines J, Santos EM, Lasmar CAP, Costa $\mathrm{CH}$, Teixeira EMB, Maia MCM, Coura F, Silva CHD, et al. (2004) BRCA1 mutations in Brazilian patients. Genet Mol Biol 27:500-504.

Meijers-Heijboer H, Wijnen J, Vasen H, Wasielewski M, Wagner A, Hollestelle A, Elstrodt F, van den Bos R, de Snoo A, Fat GT, et al. (2003) The CHEK2 1100delC mutation identifies families with a hereditary breast and colorectal cancer phenotype. Am J Hum Genet 72:1308-1314.

Miki Y, Swensen J, Shattuck-Eidens D, Futreal PA, Harshman K, Tavtigian S, Liu Q, Cochran C, Bennett LM and Ding W (1994) A strong candidate for the breast and ovarian cancer susceptibility gene BRCA1. Science 266:66-71.

Moreira MA, Bobrovnitchaia IG, Lima MA, Santos AC, Ramos JP, Souza KR, Peixoto A, Teixeira MR and Vargas FR (2012) Portuguese c.156_157insAlu BRCA2 founder mutation: Gastrointestinal and tongue neoplasias may be part of the phenotype. Fam Cancer 11:657-660.

Nelen MR, Padberg GW, Peeters EA, Lin AY, van den Helm B, Frants RR, Coulon V, Goldstein AM, van Reen MM, Easton $\mathrm{DF}$, et al. (1996) Localization of the gene for Cowden disease to chromosome 10q22-23. Nat Genet 13:114-116.

Nelson HD, Huffman LH, Fu R, Harris EL and Force, U.S. Preventive Services Task Force (2005) Genetic risk assessment and BRCA mutation testing for breast and ovarian cancer susceptibility: Systematic evidence review for the U.S. Preventive Services Task Force. Ann Intern Med 143:362-379.

Palmero EI, Ashton-Prolla P, da Rocha JC, Vargas FR, Kalakun L, Blom MB, Azevedo SJ, Caleffi M, Giugliani R and Schüler-Faccini L (2007) Clinical characterization and risk profile of individuals seeking genetic counseling for hereditary breast cancer in Brazil. J Genet Couns 16:363-371.

Palmero EI, Caleffi M, Schüler-Faccini L, Roth FL, Kalakun L, Netto CB, Skonieski G, Giacomazzi J, Weber B, Giugliani $\mathrm{R}$, et al. (2009) Population prevalence of hereditary breast cancer phenotypes and implementation of a genetic cancer risk assessment program in southern Brazil. Genet Mol Biol 32:447-455.

Payne SR, Newman B and King MC (2000) Complex germline rearrangement of BRCA1 associated with breast and ovarian cancer. Genes Chromosomes Cancer 29:58-62.

Petitjean A, Mathe E, Kato S, Ishioka C, Tavtigian SV, Hainaut P and Olivier M (2007) Impact of mutant p53 functional properties on TP53 mutation patterns and tumor phenotype: Lessons from recent developments in the IARC TP53 database. Hum Mutat 28:622-629.

Petrij-Bosch A, Peelen T, van Vliet M, van Eijk R, Olmer R, Drüsedau M, Hogervorst FB, Hageman S, Arts PJ, Ligtenberg MJ, et al. (1997) BRCA1 genomic deletions are major 
founder mutations in Dutch breast cancer patients. Nat Genet 17:341-345.

Preisler-Adams S, Schönbuchner I, Fiebig B, Welling B, Dworniczak B and Weber BH (2006) Gross rearrangements in BRCA1 but not BRCA2 play a notable role in predisposition to breast and ovarian cancer in high-risk families of German origin. Cancer Genet Cytogenet 168:44-49.

Shattuck-Eidens D, Oliphant A, McClure M, McBride C, Gupte J, Rubano T, Pruss D, Tavtigian SV, Teng DH, Adey N, et al. (1997) BRCA1 sequence analysis in women at high risk for susceptibility mutations. Risk factor analysis and implications for genetic testing. JAMA 278:1242-1250.

Silva FC, Lisboa BC, Figueiredo MC, Torrezan GT, Santos EM, Krepischi AC, Rossi BM, Achatz MI and Carraro DM (2014) Hereditary breast and ovarian cancer: Assessment of point mutations and copy number variations in Brazilian patients. BMC Med Genet 15:55.

Smith RA, Caleffi M, Albert US, Chen TH, Duffy SW, Franceschi D, Nyström L and Global Summit Early Detection and Access to Care Panel (2006) Breast cancer in limited-resource countries: Early detection and access to care. Breast J 12(Suppl 1) :S16-26.

Srivastava A, McKinnon W and Wood ME (2001) Risk of breast and ovarian cancer in women with strong family histories. Oncology (Williston Park) 15:889-902; discussion 902, 905-887, 911-813.

Tavtigian SV, Deffenbaugh AM, Yin L, Judkins T, Scholl T, Samollow PB, de Silva D, Zharkikh A and Thomas A (2006) Comprehensive statistical study of 452 BRCA1 missense substitutions with classification of eight recurrent substitutions as neutral. J Med Genet 43:295-305.

Thomassen M, Gerdes AM, Cruger D, Jensen PK and Kruse TA (2006) Low frequency of large genomic rearrangements of BRCA1 and BRCA2 in western Denmark. Cancer Genet Cytogenet 168:168-171.

Vahteristo P, Tamminen A, Karvinen P, Eerola H, Eklund C, Aaltonen LA, Blomqvist C, Aittomäki K and Nevanlinna $\mathrm{H}$ (2001) p53, CHK2, and CHK1 genes in Finnish families with Li-Fraumeni syndrome: Further evidence of CHK2 in inherited cancer predisposition. Cancer Res 61:5718-5722.
Vallée MP, Francy TC, Judkins MK, Babikyan D, Lesueur F, Gammon A, Goldgar DE, Couch FJ and Tavtigian SV (2012) Classification of missense substitutions in the BRCA genes: A database dedicated to Ex-UVs. Hum Mutat 33:2228.

Wooster R, Neuhausen SL, Mangion J, Quirk Y, Ford D, Collins N, Nguyen K, Seal S, Tran T and Averill D (1994) Localization of a breast cancer susceptibility gene, BRCA2, to chromosome 13q12-13. Science 265:2088-2090.

\section{Internet Resources}

BCI (2014) Breast Cancer International Core database, BIC, http://research.nhgri.nih.gov/bic. (accessed July10 14).

DataSUS (2014) http://www.datasus.gov.br (accessed June 18, 2014).

Globocan (2014) http://globocan.iarc.fr/Default.aspx (accessed November 2, 2014).

Government of Rio Grande do Sul, http://www.rs.gov.br (accessed November 2, 2014).

NCCN (2014) National Comprehensive Cancer Network NCCN, http://www.nccn.org (accessed September 15, 2014).

INCa (2014) National Institute of Cancer - INCa, http://www.inca.gov.br (accessed November 2, 2014).

HGMD (2014) The Human Gene Mutation Database (HGMD), http://www.hgmd.cf.ac.uk/ (accessed November 30, 2014).

\section{Supplementary Material}

The following online material mis available for this article: - Table S1 - The Family History Syndrome questionnaire This material is available as part of the online version of this article from http://www.scielo/gmb.

\section{Associate Editor: Héctor Seuanez}

License information: This is an open-access article distributed under the terms of the Creative Commons Attribution License (type CC-BY), which permits unrestricted use, distribution and reproduction in any medium, provided the original article is properly cited.

\section{Erratum}

On page 210 the author name spelled as Florence Le Calvez Kelm should read Florence Le Calvez-Kelm. 